\title{
Corrigendum
}

\section{Pathways from early adversity to later adjustment: Tests of the additive and bidirectional effects of executive control and diurnal cortisol in early childhood - CORRIGENDUM}

Liliana J. Lengua, Stephanie F. Thompson, Lyndsey R. Moran, Maureen Zalewski, Erika J. Ruberry, Melanie R. Klein and Cara J. Kiff

doi: https://doi.org/10.1017/S0954579419000373. Published online by Cambridge University Press, 10 May 2019.

Keywords: adjustment, cumulative risk, early childhood executive control, hypothalamic-pituitary-adrenal axis, income

In Lengua et al. 2020, the slope factor loadings were incorrectly The correct figure 1 follows: represented in figure 1. The loadings for executive control and diurnal cortisol were reversed.

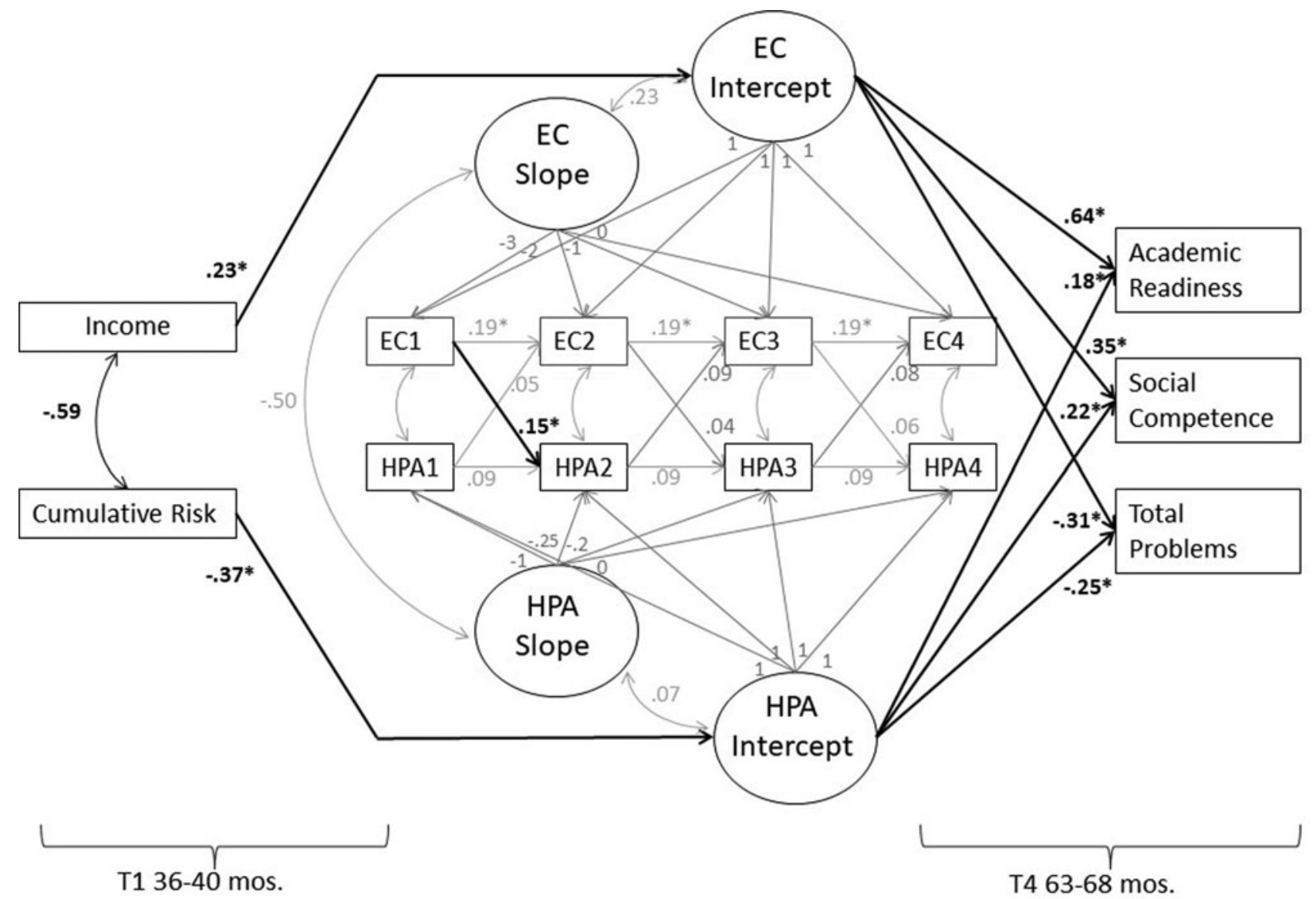

Figure 1. Model with standardized coefficients of the effects of income and cumulative risk on executive control and diurnal cortisol level, the bidirectional effects of executive control and diurnal cortisol, and their effects on children's academic readiness, social competence, and adjustment problems. Effects of child gender were covaried but are not depicted. ${ }^{*} p<.05$. 


\section{Reference}

Lengua, L., Thompson, S., Moran, L., Zalewski, M., Ruberry, E., Klein, M., \& Kiff, C. (2020). Pathways from early adversity to later adjustment: Tests of the additive and bidirectional effects of executive control and diurnal cortisol in early childhood. Development and Psychopathology, 32(2), 545-558. doi:10.1017/S0954579419000373

Cite this article: Lengua LJ, Thompson SF, Moran LR, Zalewski M, Ruberry EJ, Klein MR, Kiff CJ (2021). Pathways from early adversity to later adjustment: Tests of the additive and bidirectional effects of executive control and diurnal cortisol in early childhood Corrigendum. Development and Psychopathology 33, 1140-1141. https://doi.org/10.1017/ S0954579421000110 